\title{
BMJ Open Associations between excessive adiposity and seroprevalence of herpes simplex virus type 1 and type 2 among US adults: a population-based age-period-cohort analysis
}

\author{
Su-Hsun Liu, ${ }^{1,2}$ I-Shiang Tzeng, ${ }^{3,4}$ Tsung-Han Hsieh,, ${ }^{3,5}$ Yhu-Chering Huang ${ }^{1,6}$
}

To cite: Liu S-H, Tzeng I-S, Hsieh T-H, et al. Associations between excessive adiposity and seroprevalence of herpes simplex virus type 1 and type 2 among US adults: a population-based age-period-cohort analysis. BMJ Open 2016;6:e012571. doi:10.1136/bmjopen-2016012571

- Prepublication history and additional material is available. To view please visit the journal (http://dx.doi.org/ 10.1136/bmjopen-2016012571).

Received 9 May 2016 Revised 25 August 2016 Accepted 28 September 2016

CrossMark

For numbered affiliations see end of article.

Correspondence to

Dr Su-Hsun Liu;

shliu41@mail.cgu.edu.tw

\section{ABSTRACT}

Objectives: Evidence on the association between herpes simplex virus (HSV) and excessive adiposity, such as obesity (body mass index $\geq 30 \mathrm{~kg} / \mathrm{m}^{2}$ ) and abdominal obesity (waist circumference (WC) $>102$ or $88 \mathrm{~cm}$ ), has been inconsistent. We sought to examine whether age-period-cohort (APC) effects could explain for the observed heterogeneities.

Design: Population-based cross-sectional study. Participants: Adults aged 20-49 years with available serological data in the National Health and Nutrition Examination Survey (NHANES) in 1999-2012.

Exposure measures: Obesity and abdominal obesity. Results: In men, excessive adiposity was generally not associated with HSV1 or HSV2 (all $p>0.05$ ); however, there were positive correlations between HSV seroprevalence and excessive adiposity in certain age and birth cohort groups. Based on APC analysis, abdominally obese men aged $30-40$ years showed a nearly $20 \%$ increase in risk for HSV1 seropositivity (adjusted prevalence ratio $(\mathrm{aPR})=1.18 ; 95 \% \mathrm{Cl} 1.10$ to 1.27 ) as compared with abdominally non-obese men of the same age; there was no such association in men of other age groups. Also, men of a large WC who were born before 1962 or after 1979 had a $28 \%$ higher risk for HSV2 seropositivity than those of a normal WC in the same birth cohorts (aPR=1.28, 95\% $\mathrm{Cl} 1.17$ to 1.54); yet the association did not hold for men in other cohorts (aPR=0.86, $95 \% \mathrm{Cl} 0.64$ to 1.17 ). In women, a large WC was correlated with a minimally increased HSV1 seroprevalence (aPR $=1.07,95 \% \mathrm{Cl} 1.01$ to 1.13 ) but not with HSV2 seropositivity (aPR $=1.13 ; 95 \% \mathrm{Cl}$ 0.99 to 1.28 ). Likewise, there were strong associations between abdominal obesity and HSV2 seropositivity in subgroups of women participating in the earliest survey cycle (aPR=1.41, 95\% $\mathrm{Cl} 1.12$ to 1.78 ) but not in other survey periods (aPR $=0.94,95 \% \mathrm{Cl} 0.85$ to 1.03 ).

Conclusions: There was no consistent evidence for strong associations between HSV seropositivity and excessive adiposity in adults. APC analysis results further cautioned the generalisability of previous reports based on 1 or 2 cycles of survey data.

\section{Strengths and limitations of this study}

- The current study included data from both sexes and across multiple survey cycles to provide robust and unbiased estimates for the adiposityherpes simplex virus (HSV) associations in the US adults aged 20-49 years.

- The application of age-period-cohort analysis provided novel perspectives on explaining inconsistent findings in the literature.

- The current study could not establish the temporality of the adiposity-HSV relationship, of which the likelihood of reverse causation was equally plausible.

\section{INTRODUCTION}

Herpes simplex virus type 1 (HSV1) and type 2 (HSV2) are among the most widely spread viral pathogens in the general population worldwide. According to the recently released global estimates for HSV2 infection by WHO, more than 400 million people aged 15-49 years were seroprevalent for HSV2 in 2012, corresponding to a global prevalence estimate of $11.3 \% .^{1}$ Although an updated estimate for HSV1 will not be available until late $2015,{ }^{2}$ an early review of epidemiological studies showed a worldwide seroprevalence of HSV1 to be $40-60 \%$ or higher in the non-high-risk population. ${ }^{3}$

Besides the common clinical manifestations of painful skin or mucosal lesions, HSV1 and HSV2 have been reportedly implicated in the pathogenesis of atherosclerosis since the 1970s. ${ }^{4-6}$ Findings from early chicken models and subsequent molecular investigations have suggested that infections by the herpesvirus family, including HSV1, HSV2 and cytomegalovirus (CMV), may alter cellular cholesterol metabolism, facilitating 
lipid accumulation in the endovascular cells. ${ }^{78}$ However, epidemiological findings for a direct link of HSV infection to cardiovascular outcomes, ${ }^{9-11}$ asymptomatic atherosclerosis $^{12} 13$ or dyslipidemia ${ }^{14}$ have been inconsistent.

With the increasing recognition of high body mass index (BMI) and abdominal fatness as modifiable risk factors for cardiovascular diseases, ${ }^{15}$ studies have suggested a possible contribution of HSV to the obesity epidemic. $^{16} 17$ For example, Thjodleifsson et $a l^{16}$ showed that HSV1 antibodies were not correlated with BMI values in an European cohort of 985 adults while Schooling et $a l^{17}$ have found that HSV1 seroprevalence was positively associated with women's hip-to-waist ratio in a US-representative population. In face with accumulating evidence indicating that excessive adiposity may predispose individuals with obesity to certain infections $^{18}$ or worse infection outcomes, ${ }^{19} 20$ investigators have also hypothesised a reverse causal relationship between excessive adiposity and HSV1 ${ }^{17} \quad 21 \quad 22$ and HSV2. $^{11} 212324$ Particularly, from recently published findings based on the National Health and Nutrition Examination Survey (NHANES) data, it appears that HSV1 was probably associated with obesity in men ${ }^{22}$ and with abdominal obesity in women ${ }^{17}$ whereas study findings surrounding the role of HSV2 in excessive adiposity have remained inconsistent. ${ }^{11} 212324$

These epidemiological observations, however, were not systematically examined in adult men and women. Therefore, in the current analysis, we aimed to determine whether the association between excessive adiposity and HSV1 or HSV2 differs by host sex. Additionally, we sought to characterise any potential moderating effect of host age, survey period or birth cohort on the HSV-obesity associations using multicycle data from the NHANES.

\section{MATERIALS AND METHODS}

\section{Study design and population}

In each 2-year cycle, the continuous NHANES programme collects health-related information from the general, non-institutionalised US population since 1999. Detailed descriptions about the survey design, questionnaires used during the household interview, examinations performed on the mobile examination centre (MEC) and biospecimens acquired can be fully accessed online. $^{25}$ The National Center for Health Statistics (NCHS) has received ethical approval from NCHS Research Ethics Review Board prior to the survey. ${ }^{26}$ Briefly, after obtaining informed consent, the study personnel interviewed and examined each adult participant aged 20 or older in the household and at the MEC, respectively. Individual sociodemographic characteristics, self-reported medical history and health behaviours were comprehensively documented during the interview process. ${ }^{25}$ As the current study used publicly available, de-identified public data sets, the Institutional Review Boards of the affiliated institution has reviewed the analytics plan and waived the consenting requirement.
Data collection

Serological results of HSV-1 and HSV-2

Serum samples from the NHANES participants were stored and shipped to the affiliated laboratory at Emory University for serological tests. ${ }^{27}$ Using enzymatic immunodot assay, type-specific glycoproteins, gG-1 and gG-2, were employed to detect human antibodies to HSV-1 and to HSV-2 in sample sera, respectively. ${ }^{28}$ In-house positive and negative control sera were used for quality control. There have been no changes to the laboratory equipment or protocol since 1988. For the following analysis, we included adults aged 20-49 who participated in the NHANES in 1999-2012 and whose serological results for HSV1 and HSV2 were available.

\section{Participants' covariates}

We applied the WHO classification system to define overweight (BMI 25-29.9) and obesity $\left(\mathrm{BMI} \geq 30 \mathrm{~kg} / \mathrm{m}^{2}\right) ;^{29}$ the National Cholesterol Education Program's Adult Treatment Panel III report (ATP III, $>88 \mathrm{~cm}$ for women and $>102 \mathrm{~cm}$ for men) to determine central (or abdominal) obesity. ${ }^{30}$ Other potential confounders considered included participants' race or ethnicity (non-Hispanic white, non-Hispanic black, Mexican-American and others); marital status (married, single or living with a partner); having a college or higher degree; the annual household income (family income $\geq 2.5$ times of the national poverty index at the survey year); health insurance coverage; clinically diagnosed or treated diabetes mellitus; smoking behaviour (lifetime smoking $\geq 100$ pieces or not); recent alcohol use (12 or more drinks in the previous 12 months); number of lifetime and recent sexual partners (in the prior 12 months); reported age at sex debut ( $<16$ vs 16 years or older); self-reported frequency of condom use (not always vs always); and history of diagnosed genital herpes as well as other sexually transmitted infections such as gonorrhoea or chlamydia.

\section{Statistical analysis}

In accordance with the analytic guideline published by the NCHS, ${ }^{31}$ we applied sampling weights to account for the multilevel, stratified probability sampling method as well as the non-response rates in each survey cycle. To obtain stable population-based prevalence estimates, we evaluated for a potential period effect every two survey cycles (or equivalently every 4 years), except for the latest cycle (2011-2012). Accordingly, we grouped the survey participants into one of the 4-year age groups, with the oldest group of 48-49 years. Individuals were also categorised by their birth years ( 4 years, except for the 1991-92 cohort). We calculated and plotted weighted seroprevalence rates of HSV1 and HSV2 for each of these age groups, time periods and birth cohorts for men and women, respectively. We also compared seropositivity rates of HSV1 and HSV2 by selected participant characteristics using design-based $\chi^{2}$ test and univariate Poisson regression models. In the 
multivariable models, we retained covariates that were a priori hypothesised to potentially confound the association between adiposity and HSV or those showing significant univariate associations.

In addition, we only included at most two of age (a), period $(p)$ and cohort (c) variables in separate multivariable models each time because of the colinear nature among these three variables $(\mathrm{c}=\mathrm{p}-\mathrm{a}) .^{32}$ To identify the potential modifying effect of age, calendar period or birth year, we systemically examine the results of stratified analysis by each of these three factors in models that included age and period (AP models), or age and cohort (AC models), or period and cohort indicators (PC models) along with other important covariates. We used svy commands in Stata V.13 for all statistical analysis unless otherwise specified (Stata Statistical Software: Release 13 [program], College Station, TX, 2013), with a two-tailed significance level of 0.05. Results from negative binomial models were not different from those obtained by specifying Poisson distributions.

\section{RESULTS}

Among 15063 adults aged 20-49 who completed the MEC session between 1999 and 2012, 14101 individuals had serological data for HSV1 and HSV2 (93.6\%). After excluding adults with an abnormally low BMI value $\left(<18.5 \mathrm{~kg} / \mathrm{m}^{2}\right)$, those who denied ever having sexual activities, pregnant women as well as participants with incomplete data in one or more covariates, we included 5227 men and 4441 women for the primary analysis (see online supplementary figure $\mathrm{S} 1$ ).

For both HSV1 and HSV2, the overall increasing and decreasing trend by age and cohort, separately, was statistically significant (both $\mathrm{p}$ for trend $<0.001$, see online supplementary table S1 and figure S2). The temporal trend in HSV across the survey cycles was also apparent ( $p$ for trend $=0.007$ for HSV1 and 0.017 for HSV2, see online supplementary table $\mathrm{S} 1$ ), yet the secular change was minimal for HSV1 in women ( $p$ for trend $=0.049$ ) and for HSV2 in men ( $\mathrm{p}$ for trend=0.89). Age-associated or cohort-associated variations in the prevalence of obesity or abdominal obesity were similar to those in HSV1 or HSV2 seropositivity in men and women (see online supplementary figure S3). During the 14 years of observation, prevalence of obesity or abdominal obesity seemed unchanged in women (both $\mathrm{p}>0.05$, see online supplementary table S2) but increased substantially in men (both $\mathrm{p}$ for trend $<00.05$, see online supplementary table S2).

Table 1 shows seroprevalence estimates and comparison results of HSV1 and HSV2 among important subgroups of men and women, separately. Online supplementary table S3 displays comparison results for the overall study population. These univariate analysis revealed that seroprevalence of HSV1 and HSV2 was positively associated with abdominal obesity $(p<0.001)$ and obesity $(\mathrm{p}<0.001)$ in adult women but not in men for HSV2 ( $\mathrm{p}=0.89$ for obesity; $\mathrm{p}=0.61$ for abdominal obesity, table 1). There was also a significant doseresponse relationship between HSV seropositivity rates and women's BMI values $(p<0.001$, table 1$)$. In adult men, such positive correlation with the degree of excessive adiposity was apparent for HSV1 $(p=0.003)$ but not for HSV2 ( $\mathrm{p}=0.93$ ) seroprevalence (table 1$)$.

Men and women shared a similar sociodemographic risk profile for either HSV1 or HSV2 seropositivity. Both adult men and women were more likely to be positive for HSV1 than their counterparts if they were Mexican-American or other race/ethnicity $(74.1 \%$ in men, $77.4 \%$ in women), if they had a lower educational attainment $(61.4 \%$ in men, $64.6 \%$ in women), less household income $(63.1 \%$ in men, $66.4 \%$ in women) or if they were not covered by any health insurance plan $(63.8 \%$ in men, $68.7 \%$ in women; table 1$)$. These socioeconomic characteristics were similarly associated with a higher rate of HSV2 seropositivity, except that non-Hispanic blacks had the highest seroprevalence of HSV2 (33.6\% in men, $57.3 \%$ in women) among the three racial or ethnic groups (table 1).

Meanwhile, there were sex-specific differences in cardiovascular and sexual risk factors. For example, a selfreported hypertension or diabetes history was associated with seropositivity to HSV1 and HSV2 in women whereas, in men, the former was irrelevant to HSV2 $(p=0.49)$ and the latter not related to HSV1 ( $p=0.35$, table 1). Having five or more lifetime sex partners was indicative of a nearly $10 \%$ difference in seroprevalence of HSV1 in men $(59.8 \%$ vs $50.9 \%, \mathrm{p}<0.001)$ but was irrelevant to women's likelihood for HSV1 $(60.9 \%$ vs $59.4 \%, \mathrm{p}=0.40$ ). Furthermore, men were twice more likely to be positive for HSV2 if they reported five or more different sex partners in the previous 12 months (22.2\% vs $11.6 \%, \mathrm{p}<0.001)$; this finding was not observed in women $(\mathrm{p}=0.14)$. These sex-specific distinctions in risk factors for either adiposity or HSV justified the subsequent separate modelling for men and women.

\section{Age and period effects on HSV1-adiposity association}

Table 2 displays the results of multivariable Poisson regression models on HSV1 seroprevalence in men and women, respectively. After adjusting for age, time period and other sociodemographic as well as behavioural risk factors, a high BMI $\left(\geq 30 \mathrm{~kg} / \mathrm{m}^{2}\right)$ was not statistically associated with HSV1 seropositivity in adult men (adjusted prevalence ratio $(\mathrm{aPR})=1.06, \mathrm{p}=0.07)$ or women ( $\mathrm{aPR}=1.04, \mathrm{p}=0.14$; table 2$)$.

In men aged $20-23$ or $28-47$ years, obesity was correlated with a $13 \%$ higher HSV1 prevalence $(\mathrm{aPR}=1.13$, $\mathrm{p}<0.001)$ while in other age groups, there was no such difference in HSV1 seroprevalence by obesity status $(\mathrm{aPR}=0.91, \mathrm{p}=0.18 ; \mathrm{p}$ for interaction $<0.01$, table 2). Similarly, in women aged 32 years or older, BMI $\geq 30 \mathrm{~kg} /$ $\mathrm{m}^{2}$ was statistically associated with a higher HSV1 seroprevalence rate than non-obese women of the same 
Table 1 Weighted seroprevalence of HSV1 and HSV2 by selected characteristics in adult men $(\mathrm{N}=5227)$ and women $(\mathrm{N}=4441)$ aged $20-49$ years, NHANES 1999-2012

\begin{tabular}{|c|c|c|c|c|c|c|c|c|}
\hline \multirow[b]{3}{*}{ Characteristics } & \multicolumn{4}{|l|}{ HSV1 } & \multicolumn{4}{|l|}{ HSV2 } \\
\hline & \multicolumn{2}{|l|}{ Men } & \multicolumn{2}{|l|}{ Women } & \multicolumn{2}{|l|}{ Men } & \multicolumn{2}{|l|}{ Women } \\
\hline & Per cent & p Value & Per cent & p Value & Per cent & p Value & Per cent & p Value \\
\hline Overall & $56.9 \%$ & & $60.2 \%$ & & $12.2 \%$ & & $24.5 \%$ & \\
\hline \multicolumn{9}{|l|}{ Anthropometrics } \\
\hline \multicolumn{9}{|l|}{ Obesity $\left(\mathrm{BMl} \geq 30 \mathrm{~kg} / \mathrm{m}^{2}\right)$} \\
\hline No & $55.0 \%$ & 0.002 & $57.7 \%$ & $<0.001$ & $12.1 \%$ & 0.892 & $21.9 \%$ & $<0.001$ \\
\hline Yes & $61.2 \%$ & & $65.5 \%$ & & $12.3 \%$ & & $29.8 \%$ & \\
\hline \multicolumn{9}{|c|}{ Abdominal obesity $(\mathrm{WC}>88$ or $102 \mathrm{~cm})$} \\
\hline No & $54.8 \%$ & 0.001 & $55.2 \%$ & $<0.001$ & $12.0 \%$ & 0.608 & $19.2 \%$ & $<0.001$ \\
\hline Yes & $60.8 \%$ & & $64.6 \%$ & & $12.5 \%$ & & $29.1 \%$ & \\
\hline \multicolumn{9}{|l|}{ BMI category $\left(\mathrm{kg} / \mathrm{m}^{2}\right)$} \\
\hline $18.5-24.9$ & $53.8 \%$ & 0.003 & $54.6 \%$ & $<0.001$ & $12.1 \%$ & 0.934 & $18.1 \%$ & $<0.001$ \\
\hline 25-29.9 & $55.9 \%$ & & $62.2 \%$ & & $12.2 \%$ & & $27.6 \%$ & \\
\hline $30-34.9$ & $61.3 \%$ & & $66.0 \%$ & & $12.7 \%$ & & $28.2 \%$ & \\
\hline$\geq 35$ & $61.2 \%$ & & $65.0 \%$ & & $11.5 \%$ & & $31.3 \%$ & \\
\hline \multicolumn{9}{|l|}{ Demographics } \\
\hline \multicolumn{9}{|l|}{ Race } \\
\hline Non-Hispanic white & $51.2 \%$ & $<0.001$ & $54.0 \%$ & $<0.001$ & $9.5 \%$ & $<0.001$ & $19.0 \%$ & $<0.001$ \\
\hline Non-Hispanic black & $61.0 \%$ & & $68.1 \%$ & & $33.6 \%$ & & $57.3 \%$ & \\
\hline Mexican American and others & $74.1 \%$ & & $77.4 \%$ & & $11.6 \%$ & & $23.7 \%$ & \\
\hline \multicolumn{9}{|l|}{ Education $\geq$ college } \\
\hline No & $61.4 \%$ & $<0.001$ & $64.6 \%$ & $<0.001$ & $13.7 \%$ & $<0.001$ & $28.4 \%$ & $<0.001$ \\
\hline Yes & $45.1 \%$ & & $49.6 \%$ & & $8.1 \%$ & & $15.0 \%$ & \\
\hline \multicolumn{9}{|l|}{ Marital status } \\
\hline Married & $59.7 \%$ & 0.002 & $61.1 \%$ & 0.093 & $11.1 \%$ & 0.024 & $20.3 \%$ & $<0.001$ \\
\hline Single or divorced & $53.3 \%$ & & $57.9 \%$ & & $12.5 \%$ & & $30.4 \%$ & \\
\hline Living with a partner & $53.9 \%$ & & $63.8 \%$ & & $16.5 \%$ & & $26.3 \%$ & \\
\hline \multicolumn{9}{|l|}{ Annual household income level } \\
\hline $\mathrm{PIR}<2.5$ & $63.1 \%$ & $<0.001$ & $66.4 \%$ & $<0.001$ & $14.2 \%$ & 0.001 & $29.4 \%$ & $<0.001$ \\
\hline $\mathrm{PIR} \geq 2.5$ & $52.6 \%$ & & $55.2 \%$ & & $10.8 \%$ & & $20.5 \%$ & \\
\hline \multicolumn{9}{|l|}{ Coverage by health insurance } \\
\hline No & $63.8 \%$ & $<0.001$ & $68.7 \%$ & $<0.001$ & $15.8 \%$ & $<0.001$ & $27.9 \%$ & 0.025 \\
\hline Yes & $54.3 \%$ & & $58.1 \%$ & & $10.9 \%$ & & $23.6 \%$ & \\
\hline Risk factors & & & & & & & & \\
\hline Hypertension history & $n=5195$ & & $n=4426$ & & $n=5195$ & & $n=4426$ & \\
\hline No & $55.7 \%$ & 0.006 & $58.9 \%$ & $<0.001$ & $12.0 \%$ & 0.489 & $23.2 \%$ & 0.002 \\
\hline Yes & $61.7 \%$ & & $68.0 \%$ & & $13.0 \%$ & & $31.3 \%$ & \\
\hline Diabetes history & $n=5192$ & & $n=4406$ & & $n=5192$ & & $n=4406$ & \\
\hline No & $56.7 \%$ & 0.352 & $59.5 \%$ & $<0.001$ & $12.0 \%$ & 0.028 & $24.1 \%$ & 0.007 \\
\hline Yes & $61.3 \%$ & & $80.0 \%$ & & $17.5 \%$ & & $36.0 \%$ & \\
\hline$\geq 12$ drinks in past 12 months & $n=5224$ & & $n=4436$ & & $n=5224$ & & $n=4436$ & \\
\hline No & $60.4 \%$ & 0.146 & $65.6 \%$ & $<0.001$ & $8.8 \%$ & 0.009 & $24.0 \%$ & 0.730 \\
\hline Yes & $56.4 \%$ & & $58.4 \%$ & & $12.6 \%$ & & $24.7 \%$ & \\
\hline Lifetime smoking $\geq 100$ pieces & & & & & & & & \\
\hline No & $53.9 \%$ & $<0.001$ & $57.9 \%$ & 0.004 & $9.7 \%$ & $<0.001$ & $19.4 \%$ & $<0.001$ \\
\hline Yes & $59.9 \%$ & & $63.5 \%$ & & $14.7 \%$ & & $31.4 \%$ & \\
\hline Lifetime sex partners $\geq 5$ & & & & & & & & \\
\hline No & $50.9 \%$ & $<0.001$ & $59.4 \%$ & 0.401 & $5.7 \%$ & $<0.001$ & $14.8 \%$ & $<0.001$ \\
\hline Yes & $59.8 \%$ & & $60.9 \%$ & & $15.4 \%$ & & $32.1 \%$ & \\
\hline Recent sex partners $\geq 5$ in prior 1 & months & & & & & & & \\
\hline No & $56.8 \%$ & 0.520 & $60.3 \%$ & 0.506 & $11.6 \%$ & $<0.001$ & $24.3 \%$ & 0.139 \\
\hline Yes & $59.3 \%$ & & $56.8 \%$ & & $22.2 \%$ & & $32.3 \%$ & \\
\hline Ever having genital herpes & & & & & & & & \\
\hline No & $57.0 \%$ & 0.547 & $61.0 \%$ & 0.002 & $10.8 \%$ & $<0.001$ & $21.3 \%$ & $<0.001$ \\
\hline Yes & $53.5 \%$ & & $48.2 \%$ & & $74.4 \%$ & & $74.4 \%$ & \\
\hline
\end{tabular}


Table 1 Continued

\begin{tabular}{|c|c|c|c|c|c|c|c|c|}
\hline \multirow[b]{3}{*}{ Characteristics } & \multicolumn{4}{|l|}{ HSV1 } & \multicolumn{4}{|l|}{ HSV2 } \\
\hline & \multicolumn{2}{|l|}{ Men } & \multicolumn{2}{|l|}{ Women } & \multicolumn{2}{|l|}{ Men } & \multicolumn{2}{|l|}{ Women } \\
\hline & Per cent & p Value & Per cent & p Value & Per cent & p Value & Per cent & p Value \\
\hline Sex debut before age 16 & $n=5222$ & & $n=4436$ & & $n=5222$ & & $n=4436$ & \\
\hline No & $61.7 \%$ & $<0.001$ & $63.9 \%$ & 0.011 & $18.2 \%$ & $<0.001$ & $33.0 \%$ & $<0.001$ \\
\hline Yes & $54.6 \%$ & & $58.8 \%$ & & $9.4 \%$ & & $21.1 \%$ & \\
\hline Using condom & $n=3561$ & & $n=2951$ & & $n=3561$ & & $n=2951$ & \\
\hline Not always & $54.8 \%$ & 0.732 & $59.5 \%$ & 0.144 & $14.1 \%$ & 0.397 & $28.2 \%$ & 0.050 \\
\hline Always & $55.8 \%$ & & $54.8 \%$ & & $12.6 \%$ & & $22.7 \%$ & \\
\hline
\end{tabular}

BMI, body mass index; HSV, herpes simplex virus; PIR, poverty index ratio; WC, waist circumference.

age $(\mathrm{aPR}=1.10, \mathrm{p}<0.01)$ whereas younger women $(24-$ 31 years) had a comparable HSV1 prevalence regardless of their $\mathrm{BMI}$ values $(\mathrm{aPR}=0.95, \mathrm{p}=0.43$; $\mathrm{p}$ for interaction=0.02, table 2). Similarly, there was statistical evidence suggesting differential age $(\mathrm{p}$ for interaction $=0.001$ ) and period effects ( $\mathrm{p}$ for interaction $<0.001$ ) on the association between abdominal obesity and HSV1 seropositivity in men $(\mathrm{WC}>102 \mathrm{~cm})$ and women (WC>88 cm), respectively (table 2 ).

\section{Cohort and period effects on HSV2-adiposity association}

Overall, seropositivity of HSV2 was again not associated with obesity or abdominal obesity in men or women after adjusting for host age, birth years and other important covariates (both p>0.05, table 3). Nevertheless, there were statistically significant cohort ( $p$ for interaction=0.02) and period effects ( $p$ for interaction=0.01) moderating the associations between abdominal obesity and HSV2 seropositivity in men and women, separately (table 3). Specifically, men with abdominal obesity born in 1951-1962, 1967-1974 or 1979-1992 showed a 28\% increase in HSV2 seroprevalence as compared with those without abdominal obesity $(\mathrm{aPR}=1.28, \mathrm{p}=0.01)$; there was no such relationship between abdominal obesity and HSV2 in men belonging to other birth cohorts $(\mathrm{aPR}=0.86, \mathrm{p}=0.35$; table 3$)$.

As compared with women born in 1991-1992, women who were born before 1990 and had a WC> $>88 \mathrm{~cm}$ appeared to have a higher likelihood for HSV2 seropositivity than those with a smaller WC in the same cohorts $(\mathrm{aPR}=1.24, \mathrm{p}=0.001)$; such cohort effect was not statistically significant ( $\mathrm{p}$ for interaction $=0.28$, table 3 ). However, abdominal obesity was associated with a $41 \%$ increase in HSV2 seroprevalence only for those who

Table 2 Results of multivariable-adjusted Poisson regression on seropositivity of HSV1 by obesity or abdominal obesity for adult men and women, separately, NHANES 1999-2012

\begin{tabular}{|c|c|c|c|c|c|c|c|c|c|}
\hline & \multicolumn{4}{|c|}{ Obesity } & & \multicolumn{4}{|c|}{ Abdominal obesity } \\
\hline & $\overline{\mathbf{N}}$ & aPR $^{*}$ & LL & UL & & $\overline{\mathbf{N}}$ & aPR $^{*}$ & LL & $\overline{U L}$ \\
\hline \multicolumn{5}{|l|}{ Men } & Men & & & & \\
\hline Overall & 5227 & 1.06 & 1.00 & 1.13 & Overall & 5227 & 1.05 & 0.99 & 1.12 \\
\hline \multicolumn{5}{|l|}{ Age (years) } & Age (years) & & & & \\
\hline 24-27 or 48-49† & 976 & 0.91 & 0.78 & 1.05 & $24-27,40-43$ or $48-49 \ddagger$ & 1723 & 0.98 & 0.89 & 1.07 \\
\hline Other age groups & 4251 & 1.13 & 1.05 & 1.21 & Other age groups & 3504 & 1.18 & 1.10 & 1.27 \\
\hline \multicolumn{5}{|l|}{ Women } & Women & & & & \\
\hline Overall & 4441 & 1.04 & 0.99 & 1.10 & Overall & 4441 & 1.07 & 1.01 & 1.13 \\
\hline \multicolumn{5}{|l|}{ Age (years) } & Age (years) & & & & \\
\hline $24-27$ or $28-31 \S$ & 1196 & 0.95 & 0.85 & 1.07 & $24-279$ & 563 & 1.03 & 0.86 & 1.23 \\
\hline Others & 3245 & 1.10 & 1.03 & 1.17 & Other age groups & 3878 & 1.12 & 1.06 & 1.19 \\
\hline \multicolumn{5}{|l|}{ Period } & Period & & & & \\
\hline 1999-2002, 2011-12 & 1784 & 0.97 & 0.89 & 1.05 & $1999-2002^{* *}$ & 1152 & 0.94 & 0.85 & 1.03 \\
\hline 2003-2010†† & 2657 & 1.10 & 1.02 & 1.19 & 2003-2012 & 3289 & 1.13 & 1.06 & 1.22 \\
\hline \multicolumn{10}{|c|}{ 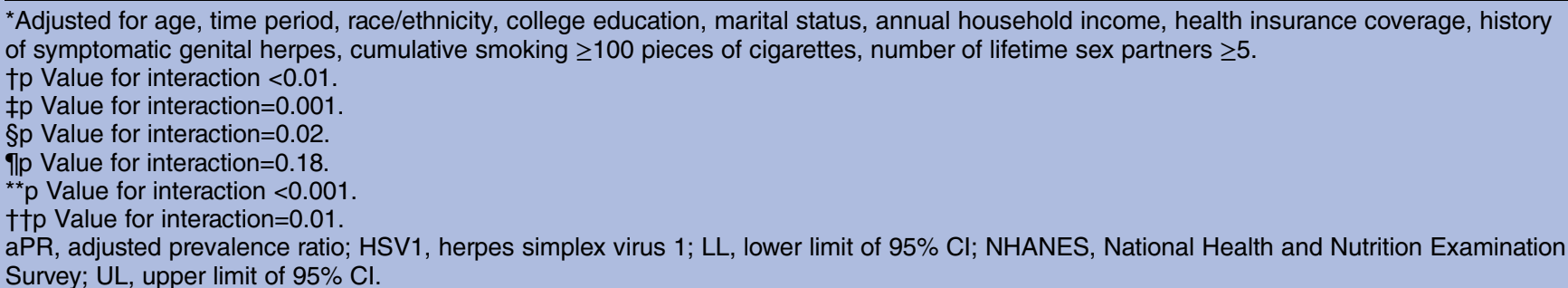 } \\
\hline
\end{tabular}


Table 3 Results of multivariable-adjusted Poisson regression on seropositivity of HSV2 by obesity or abdominal obesity for adult men and women, separately, NHANES 1999-2012

\begin{tabular}{|c|c|c|c|c|c|c|c|c|c|}
\hline & \multicolumn{4}{|c|}{ Obesity } & & \multicolumn{4}{|c|}{ Abdominal obesity } \\
\hline & $\overline{\mathbf{N}}$ & aPR $^{*}$ & LL & UL & & $\overline{\mathbf{N}}$ & aPR $^{*}$ & LL & UL \\
\hline Men & & & & & Men & & & & \\
\hline Overall & 5227 & 0.96 & 0.81 & 1.13 & Overall & 5227 & 0.99 & 0.85 & 1.14 \\
\hline Cohort & & & & & Cohort & & & & \\
\hline $1983-86 \dagger$ & 431 & 0.55 & 0.23 & 1.34 & $1963-66$ or $1975-78 \ddagger$ & 1443 & 0.86 & 0.64 & 1.17 \\
\hline Other birth cohorts & 4796 & 1.05 & 0.88 & 1.24 & Other birth cohorts & 3784 & 1.28 & 1.17 & 1.54 \\
\hline Women & & & & & Women & & & & \\
\hline Overall & 4441 & 1.04 & 0.91 & 1.19 & Overall & 4441 & 1.13 & 0.99 & 1.28 \\
\hline Cohort & & & & & Cohort & & & & \\
\hline $1959-62$ or $1991-92 \S$ & 417 & 0.87 & 0.60 & 1.25 & 1991-92ף & 51 & ** & ** & ** \\
\hline Other birth cohorts & 4024 & 1.15 & 1.00 & 1.32 & 1951-1990 & 4390 & 1.24 & 1.09 & 1.41 \\
\hline Period & & & & & Period & & & & \\
\hline 2003-2006†† & 1169 & 1.32 & 1.00 & 1.74 & 1999-2002†‡ & 1801 & 1.41 & 1.12 & 1.78 \\
\hline Other time periods & 3272 & 1.02 & 0.88 & 1.18 & 2003-2012 & 2640 & 0.99 & 0.85 & 1.16 \\
\hline
\end{tabular}

*Adjusted for time period, birth cohort, race/ethnicity, college education, marital status, annual household income, health insurance coverage, history of symptomatic genital herpes, cumulative smoking $\geq 100$ pieces of cigarettes, number of lifetime sex partners $\geq 5$.

tp Value for interaction $=0.06$

$\ddagger \mathrm{p}$ Value for interaction $=0.02$.

sp Value for interaction $=0.10$.

Ip Value for interaction $=0.28$

$* *$ Non-convergence of the model.

††p Value for interaction $=0.08$

$\ddagger \ddagger p$ Value for interaction $=0.01$

aPR, adjusted prevalence ratio; HSV2, herpes simplex virus 2; LL, lower limit of 95\% Cl; NHANES, National Health and Nutrition Examination Survey; UL, upper limit of $95 \% \mathrm{Cl}$.

enrolled in 1999-2002 (aPR=1.41, $\mathrm{p}<0.01)$ but not for women in later survey cycles $(\mathrm{aPR}=0.99, \mathrm{p}=0.92$; table 3 ).

\section{DISCUSSION}

In the current study, we used multiyear US populationbased survey data and thoroughly examined the relationship between obesity/abdominal obesity and seroprevalence of HSV1 and HSV2 in adult men and women, respectively. We found that excessive adiposity was in general not associated with seropositivity to HSV1 or HSV2 after adjusting for age, socioeconomic and behavioural factors in adult men and women. The only exception was a minimal, $7 \%$ increase in HSV1 prevalence in abdominally obese women as compared with women with a normal WC.

The finding about abdominal obesity was consistent to some degree with an early report by Schooling et $a l^{17}$ that HSV1 was associated with a high waist-to-hip ratio for women but not for men in the NHANES III. The general lack of associations between excessive adiposity and HSV2 was also in accordance with early results from NHANES. ${ }^{17} 2324$ However, results of the present analysis on HSV1 seroprevalence were in contrast to previous findings about obesity in men based on single-cycle NHANES data (2007-2008). ${ }^{22}$ Neither did our results agree with prior findings regarding HSV1 and overweight $\left(\mathrm{BMI} \geq 27 \mathrm{~kg} / \mathrm{m}^{2}\right)$, BMI values ${ }^{16}$ nor fat mass as measured by bioelectrical impedance ${ }^{21}$ in two independent European populations (table 4).
Based on the results of multivariable-adjusted models (including age and period, thus $A P$ ) for HSV1 seropositivity (table 2), we noticed, particularly for men, riskmodifying effects by age on the adiposity-HSV1 relationship, which was independent of common environmental exposures during the same calendar periods. These shared environmental factors may include obesogenicdietary choices and sedentary lifestyle that contribute to the surging obesity epidemic (especially for men) as well as improved sanitation and personal hygiene associated with declining transmission risks for HSV1 ${ }^{33}$ In separate, sex-specific multivariable models for HSV1 that replaced period with cohort indicators (AC-adjusted models); we also noted similar age-modifying effects on the adiposity-HSV1 association that were independent of cohort effects (for men, see online supplementary table S4). In comparison, there was no similar age-modifying effect on HSV2 seroprevalence for men or women.

Results of the current study suggested strong period effects on the association of adiposity with HSV1 (table 2) and with HSV2 (table 3) in women. There was also evidence for cohort effects on the visceral adiposityHSV2 relation in men (table 3). As there have been two major changes in the sample design since the beginning of the new-generation NHANES programme in $1999,{ }^{31}$ it may be argued that both the period and cohort effects were biased observations due to the changing sampling schemes. The first change administered was in NHANES 2007-2010, in which all Hispanic, instead of merely Mexican-American Hispanic, individuals were 


\begin{tabular}{|c|c|c|c|c|c|c|c|c|c|}
\hline $\begin{array}{l}\text { Authors } \\
\text { (reference) }\end{array}$ & Year & $\begin{array}{l}\text { Study } \\
\text { population }\end{array}$ & Sex & $\begin{array}{l}\text { Age } \\
\text { range; } \\
\text { mean } \\
\text { (SD) }\end{array}$ & $\begin{array}{l}\text { Anthropometric } \\
\text { measures }\end{array}$ & $\begin{array}{l}\text { Virus } \\
\text { type }\end{array}$ & $\begin{array}{l}\text { Hypothesis } \\
\text { direction }\end{array}$ & Results & Note \\
\hline $\begin{array}{l}\text { Nagelkerke } \\
\text { et } \mathrm{a}^{R^{3}}\end{array}$ & 2006 & $\begin{array}{l}\text { NHANES } \\
1999-2000\end{array}$ & $\begin{array}{l}979 \text { Men, } \\
1250 \text { women }\end{array}$ & $\begin{array}{l}\text { M: } 34.4 \\
(8.5), F: \\
33.6(8.5)\end{array}$ & $\begin{array}{l}\text { Overweight } \\
(\mathrm{BMl}>25) \text {, obese } \\
(\mathrm{BMl}>30)\end{array}$ & HSV2 & Obesity $\rightarrow$ infection & $\begin{array}{l}\text { Being obese or overweight } \\
\text { was not associated with } \\
\text { HSV2 antibodies. }\end{array}$ & $\begin{array}{l}\text { Not related in men } \\
\text { or women }\end{array}$ \\
\hline Wee et $a R^{4}$ & 2008 & $\begin{array}{l}\text { NHANES } \\
1999-2004\end{array}$ & 3329 Women & $20-59$ & Obesity (BMI $\geq 30)$ & HSV2 & Obesity $\rightarrow$ infection & $\begin{array}{l}\text { Higher BMI was not } \\
\text { associated with HSV2 } \\
\text { seropositivity after } \\
\text { adjustment. }\end{array}$ & $\begin{array}{l}\text { Not related in } \\
\text { women }\end{array}$ \\
\hline $\begin{array}{l}\text { Schooling } \\
\text { et } a l^{17}\end{array}$ & 2011 & $\begin{array}{l}\text { NHANES III } \\
\text { 1988-1994 }\end{array}$ & $\begin{array}{l}5670 \text { Men, } \\
5836 \text { women; } \\
4561 \text { men, } \\
5013 \text { women }\end{array}$ & $\geq 17$ & $\begin{array}{l}\text { SDs of abdominal } \\
\text { obesity (WHR) and } \\
\text { BMI }\end{array}$ & $\begin{array}{l}\text { HSV1, } \\
\text { HSV2 }\end{array}$ & Infection $\rightarrow$ obesity & $\begin{array}{l}\text { 'Childhood' pathogens, } \\
\text { including HSV1 were } \\
\text { positively associated with } \\
\text { WHR among women but not } \\
\text { men after adjustment. }\end{array}$ & $\begin{array}{l}\text { HSV1 infection was } \\
\text { associated with } \\
\text { abdominal obesity in } \\
\text { women. }\end{array}$ \\
\hline $\begin{array}{l}\text { Karjala } \\
\text { et } a^{R^{2}}\end{array}$ & 2012 & $\begin{array}{l}\text { NHANES } \\
2007-2008\end{array}$ & 1536 Men & $20-49$ & Obesity $(\mathrm{BMI} \geq 30)$ & HSV1 & Obesity $\rightarrow$ infection & $\begin{array}{l}\text { Having a BMI classified as } \\
\text { the obese group (BMI 30- } \\
\text { 39.9) was significantly } \\
\text { associated with HSV1 } \\
\text { infection before and after } \\
\text { adjustment. }\end{array}$ & $\begin{array}{l}\text { Obesity may } \\
\text { increase the risk for } \\
\text { HSV1 infection in } \\
\text { men. }\end{array}$ \\
\hline $\begin{array}{l}\text { Mendy } \\
\text { et } a l^{11}\end{array}$ & 2013 & $\begin{array}{l}\text { NHANES } \\
1999-2010\end{array}$ & $\begin{array}{l}6674 \text { Men, } \\
7741 \text { women }\end{array}$ & $\begin{array}{l}20-49 \\
34.3\end{array}$ & $\mathrm{BMI}$ & $\begin{array}{l}\text { HSV1, } \\
\text { HSV2 }\end{array}$ & Infection $\rightarrow$ CVD & $\begin{array}{l}\text { BMI was significantly higher } \\
\text { in HSV2 seropositive } \\
\text { participants than in those } \\
\text { seronegative for HSV or } \\
\text { seropositive for HSV1 } \\
\text { (unadjusted). }\end{array}$ & $\begin{array}{l}\text { HSV2 was } \\
\text { associated with } \\
\text { premature CVD but } \\
\text { not HSV1 in adults } \\
\text { (not stratified by } \\
\text { sex). }\end{array}$ \\
\hline
\end{tabular}

BMI, body mass index; CVD (self-reported) cardiovascular disease; F, females; HSV, herpes simplex virus; M, males; NHANES, National Health and Nutrition Examination Survey; WHR, waist-to-hip ratio. 
oversampled. The second was in NHANES 2011-2014 during which cycles, Asians were oversampled along with other oversampled subgroups of Hispanics as well as non-Hispanic blacks, low-income whites and others who have been oversampled since 1999. ${ }^{31} 34$

In ad hoc sensitivity analysis that only included non-Hispanic white and black participants, however, all significant period and cohort effects on the adiposityHSV associations for women (see online supplementary table S5) and for men (see online supplementary table S6) remained persistent; the only exception being the obesity-HSV2 association for women, in which there were no more observable period effects (see online supplementary table S5). While the obesity epidemic in the USA has been driven by period or cohort effects remains debatable, ${ }^{35}$ it is likely that the secular or cohort differences in adiposity effects on HSV1 and HSV2 seropositivity resulted from sex-specific temporal trends in HSV, excessive adiposity or both. However, results of the aforementioned sensitivity analysis on a (relatively) less biased subpopulation cannot exclude the possibility of period or cohort effects. Additional investigations either on specific ethnic or racial populations or using prospective data are needed to further confirm these period-dependent and cohort-dependent associations between excessive adiposity and HSV.

Moreover, we have constructed age-period-cohort models to verify the observed cohort effects. Under the constraint-based estimation framework, ${ }^{32}$ we fitted the 2-year age, period and cohort data ${ }^{36}$ using Poisson regression models as suggested by Carstensen via the 'Epi' package $^{37}$ for R V.3.1.2 (R Core Team. R: A language and environment for statistical computing [program]. Vienna, Austria: R Foundation for Statistical Computing, 2015). In spite of few exceptions (see online supplementary figures S4 and S5), the results of variance (or deviance) analysis have consistently indicated a much greater contribution of cohort membership than the survey cycle to the adiposity-HSV relation. We have adopted models that assumed no overall changes in the secular trend and found that there were consistent, positive differences in cohort effects comparing persons with obesity to those without obesity (or abdominal obesity), particularly for adult men (see online supplementary figure S6). On the other hand, there were varying cohort effects on the obesity-HSV1 association in women, showing a greater influence of cohort effects on early, non-obese cohorts (1952-1969) and then on recent, obese cohorts (see online supplementary figure S5). Moreover, we noticed differential cohort effects on the obesity-HSV2 relationship for women in early versus recent birth cohorts (see online supplementary figure $\mathrm{S} 6$ ).

\section{Limitations}

Considering the epidemiological evidence showing that $40-60 \%$ of US adolescents have seroconverted to HSV1 positivity by age 20 and the time lag towards the seemingly most affected age groups (10-20 years after primary acquisition), ${ }^{3} 38$ our subgroup findings may support a hypothetic role of HSV1 in the current epidemics of excessive adiposity as seen in middle-aged men and women (table 2). Nevertheless, residual confounding due to unmeasured individual characteristics and behaviours that were simultaneously associated with age and a risk for increased adiposity and HSV1 seroprevalence was equally likely to explain for the found associations. Given the cross-sectional design, the speculated causal relations need to be prospectively evaluated in a cohort of infected and uninfected individuals without excessive adiposity at enrolment.

To elucidate the possibility of biased period and cohort effects, we reported results of sensitivity analysis that excluded oversampled racial/ethnic groups. Yet, the ad hoc subgroup analysis was not comprehensive in that we did not thoroughly compare results in all possible subgroups, such as those with lower household income or non-Hispanic black persons. The sample size was not sufficiently large for testing all subgroup effects. It was likely that period or cohort effects were also subgroupdependent. Regardless, neither the primary analysis nor the ad hoc subgroup analysis was poised to identify cohort or period effects in specific racial or ethnic subpopulations.

Although the current literature supports a possible bidirectional association between HSV and excessive adiposity, ${ }^{7} 817$ the current study considered potential period and cohort effects only in one direction of the hypothesis (excessive adiposity causing detectable seropositivity). We have assumed that the duration of being obese or centrally obese was irrelevant to its influence on the seropositivity to HSV1 or HSV2. We have also ignored the possibility that the adiposity-infection relation could be unequally affected by the duration of being seropositive for HSV1 or HSV2. Using age at sex debut as a surrogate for the initial exposure for HSV2, we did not find differences in HSV2 seroprevalence by age at first sex; there were no comparable covariates to approximate early exposure to HSV1.

In summary, based on the multiyear NHANES data, we showed that there was no significant overall association between excessive adiposity and HSV in adult men or women aged 20-49 years. Although seemingly datadriven in nature, there were substantial subgroup effects varying by age, calendar time and birth cohort, suggesting that early reports based on one or few survey cycles might not be readily generalisable. Definitive evidence requires prospective investigations to further elucidate the potential bidirectional association between excessive adiposity and HSV infection.

\section{Author affiliations}

${ }^{1}$ College of Medicine, Chang Gung University, Taoyuan City, Taiwan ${ }^{2}$ Department of Family Medicine, Chang Gung Memorial Hospital, Taoyuan City, Taiwan

${ }^{3}$ Department of Emergency Medicine, Chang Gung Memorial Hospital, Taoyuan City, Taiwan

${ }^{4}$ Institute of Epidemiology and Preventive Medicine, National Taiwan University, Taipei, Taiwan 
${ }^{5}$ Department of Laboratory Medicine, Chang Gung Memorial Hospital, Taoyuan City, Taiwan

${ }^{6}$ Department of Pediatrics, Chang Gung Memorial Hospital, Taoyuan City, Taiwan

Contributors S-HL, I-ST and Y-CH designed the study. S-HL, I-ST and T-HH conducted the research and analysed the data. S-HL prepared the manuscript. S-HL, I-ST, T-HH and Y-CH interpreted the results, contributed to the discussion and reviewed the manuscript. S-HL had primary responsibility for the final content

Funding This work received no specific grant from any funding agency in the public, commercial or not-for-profit sectors.

Ethics approval The Institutional Review Boards of Chang Gung Medical Institution has reviewed and approved the study protocol and the analytic plan; the consenting requirement was also waived due to the use of deidentified data sets.

\section{Competing interests None declared.}

Provenance and peer review Not commissioned; externally peer reviewed.

Data sharing statement NHANES data sets are available online (http://www. cdc.gov/nchs/nhanes/nhanes_questionnaires.htm) and statistical codes for Stata and for $\mathrm{R}$ are available on request.

Open Access This is an Open Access article distributed in accordance with the Creative Commons Attribution Non Commercial (CC BY-NC 4.0) license, which permits others to distribute, remix, adapt, build upon this work noncommercially, and license their derivative works on different terms, provided the original work is properly cited and the use is non-commercial. See: http:// creativecommons.org/licenses/by-nc/4.0/

\section{REFERENCES}

1. Looker KJ, Magaret AS, Turner KME, et al. Global estimates of prevalent and incident herpes simplex virus type 2 infections in 2012. PLOS ONE 2015;10:e114989.

2. Herpes simplex virus: World Health Organization. http://www.who.int/ mediacentre/factsheets/fs400/en

3. Smith JS, Robison NJ. Age-specific prevalence of infection with herpes simplex virus types 2 and 1: a global review. $J$ Infect Dis 2002;186(Suppl 1):S3-28.

4. Minick CR, Fabricant CG, Fabricant J, et al. Atheroarteriosclerosis induced by infection by herpesvirus. Am J Pathol 1978;96:673-706.

5. Cunningham MJ, Pasternak RC. The potential role of viruses in the pathogenesis of atherosclerosis. Circulation 1988;77:964-6.

6. Nicholson AC, Hajjar DP. Herpesviruses in atherosclerosis and thrombosis: etiolgic agents or ubiquitous bystanders? Arterioscler Thromb Vasc Biol 1998;18:339-48.

7. Hajjar DP, Nicholson AC, Hajjar KA, et al. Decreased messenger RNA translation in herpesvirus-infected arterial cells: effects on cholesterol ester hydrolase. Proc Natl Acad Sci USA 1989:86:3366-70.

8. Hajjar DP, Pomerantz KB, Falcone DJ, et al. Herpes simplex virus infection in human arterial cells. Implications in arteriosclerosis. J Clin Invest 1987;80:1317-21.

9. Havlik RJ, Blackwelder WC, Kaslow R, et al. Unlikely association between clinically apparent herpesvirus infection and coronary incidence at older ages: the Framingham Heart Study. Arteriosclerosis 1989;9:877-80.

10. Siscovick DS, Schwartz SM, Corey L, et al. Chlamydia pneumoniae, herpes simplex virus type 1 , and cytomegalovirus and incident myocardial infarction and coronary heart disease death in older adults : the Cardiovascular Health Study. Circulation 2000;102:2335-40.

11. Mendy A, Vieira ER, Gasana J. Seropositivity to herpes simplex virus type 2 , but not type 1 is associated with premature cardiovascular diseases: a population-based cross-sectional study. Atherosclerosis 2013;231:18-21.

12. Sorlie PD, Adam E, Melnick SL, et al. Cytomegalovirus/Herpesvirus and carotid atherosclerosis: the ARIC Study. J Med Virol 1994;42: 33-7.

13. Szklo M, Ding J, Tsayi MY, et al. Individual pathogens, pathogen burden and markers of subclinical atherosclerosis: the Multi-Ethnic Study of Atherosclerosis. J Cardiovasc Med 2009;10:747-51.
14. Vilkuna-Rautiainen T, Pussinen PJ, Roivainen M, et al. Serum antibody response to periodontal pathogens and herpes simplex virus in relation to classic risk factors of cardiovascular disease. Int $J$ Epidemiol 2006;35:1486-94.

15. Wormser D, Kaptoge S, Di Angelantonio E, et al. Separate and combined associations of body-mass index and abdominal adiposity with cardiovascular disease: collaborative analysis of 58 prospective studies. Lancet 2011;377:1085-95.

16. Thjodleifsson B, Olafsson I, Gislason D, et al. Infections and obesity a multinational epidemiological study. Scand J Infect Dis 2008;40:381-6.

17. Schooling CM, Jones HE, Leung GM. Lifecourse infectious origins of sexual inequalities in central adiposity. Int $J$ Epidemiol 2011;40:1556-64.

18. Falagas ME, Kompoti M. Obesity and infection. Lancet Infect Dis 2006;6:438-46.

19. Huttunen R, Syrjanen J. Obesity and the outcome of infection. Lancet Infect Dis 2010;10:442-3.

20. Falagas ME, Athanasioulia AP, Peppa G, et al. Effect of body mass index on the outcome of infections: a systematic review. Obes Rev 2009;10:280-9.

21. Fernandez-Real JM, Ferri MJ, Vendrell J, et al. Burden of infection and fat mass in healthy middle-aged men. Obesity (Silver Spring) 2007;15:245-52.

22. Karjala Z, Neal D, Rohrer J. Association between HSV1 seropositivity and obesity: data from the National Health and Nutritional Examination Survey, 2007-2008. PLOS ONE 2011;6: e19092.

23. Nagelkerke NJ, Bernsen RM, Sgaier SK, et al. Body mass index sexual behaviour, and sexually transmitted infections: an analysis using the NHANES 1999-2000 data. BMC Public Health 2006;6:199.

24. Wee CC, Huang A, Huskey KW, et al. Obesity and the likelihood of sexual behavioral risk factors for HPV and cervical cancer. Obesity (Silver Spring) 2008;16:2552-5.

25. Centers for Disease Control and Prevention CDC, National Center for Health Statistics NCHS. National Health and Nutrition Examination Survey Data. Hyattsville, MD: U.S. Department of Health and Human Services, Centers for Disease Control and Prevention. http://www.cdc.gov/nchs/nhanes/about_nhanes.htm

26. NCHS Research Ethics Review Board (ERB) Approval: Centers for Disease Control and Prevention, C.D.C. http://www.cdc.gov/nchs/ nhanes/irba98.htm

27. Lee FK, Gibson T. Laboratory procedure manual- herpes simplex virus type 1 \& 2. Emory University, 2011.

28. Ashley RL, Militoni J, Lee F, et al. Comparison of Western blot (immunoblot) and glycoprotein G-specific immunodot enzyme assay for detecting antibodies to herpes simplex virus types 1 and 2 in human sera. J Clin Microbiol 1988;26:662-7.

29. WHO. BMI classification. Geneva: World Health Organization. http:// apps.who.int/bmi/index.jsp?introPage=intro_3.html

30. Grundy SM, Brewer HB Jr, Cleeman JI, et al. Definition of metabolic syndrome: report of the National Heart, Lung, and Blood Institute/ American Heart Association conference on scientific issues related to definition. Circulation 2004;109:433-8.

31. Johnson CL, Paulose-Ram R, Ogden CL. National Health and Nutrition Examination Survey: analytic guidelines, 1999-2010. DHHS, National Center for Health Statistics, 2013.

32. Holford TR. Understanding the effects of age, period, and cohort on incidence and mortality rates. Ann Rev Public Health 1991:12:425-57.

33. Bradley H, Markowitz LE, Gibson T, et al. Seroprevalence of herpes simplex virus types 1 and 2-United States, 1999-2010. J Infect Dis 2014;209:325-33.

34. Center for Disease Control and Prevention. National Health and Nutrition Examination Survey: Analytic Guidelines, 2011-2012. Centers for Disease Control and Prevention CDC, National Centers for Health Statistics, 2013.

35. Keyes KM, Utz RL, Robinson W, et al. What is a cohort effect? Comparison of three statistical methods for modeling cohort effects in obesity prevalence in the United States, 1971-2006. Soc Sci Med 2010;70:1100-8.

36. Rutherford MJ, Lambert PC, Thompson JR. Age-period-cohort modeling. Stata J 2010;10:606-27.

37. Carstensen B. Age-period-cohort models for the Lexis diagram. Stat Med 2007;26:3018-45.

38. Beydoun HA, Dail J, Ugwu B, et al. Socio-demographic and behavioral correlates of herpes simplex virus type 1 and 2 infections and co-infections among adults in the USA. Int $J$ Infect Dis 2010;14 (Suppl 3):e154-60. 